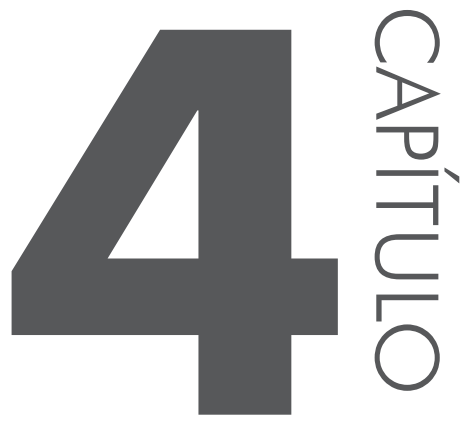

\title{
JUST IN TIME E AS RELAÇÕES DE TRABALHO NA MONTADORA MITSUBISHI MOTORS DO BRASIL S.A.
}

Magda Valéria da Silva Mônica Kélen da Silva Martins

Resumo: O presente texto objetiva refletir sobre o processo de reestruturação produtiva do capital mediante os princípios do Toyotismo e, assim, apresentar os principais impactos no trabalho e nas relações de trabalho. O Toyotismo implementa no espaço fabril os sistemas de gestão e gerenciamento do processo produtivo denominados Just in Time e Kanban. Adota-se como objeto analítico a linha de produção da montadora Mitsubishi Motors do Brasil S.A., localizada em Catalão-GO. Especificamente, almeja-se apresentar os princípios do Just in Time e Kanban, assim como as técnicas de abastecimentos e de reposição de peças adotadas na linha de produção desta montadora (andon, supermercados e sequenciado e kaisen) e, ainda, refletir sobre os impactos desses procedimentos 
sobre o trabalho e o trabalhador (polivalência/multifuncionalidade, trabalho em grupo e terceirização). Em termos metodológicos, o texto se estrutura a partir de leituras e pesquisas bibliográficas, comparadas com observações da linha de montagem realizadas durante três visitas de campo. Contudo, as análises apresentadas pautam-se por pressupostos teórico-metodológicos da ciência geográfica e visam contribuir para que reflexões mais aprofundadas sobre o modelo de produção adotado pela montadora, bem como seus impactos no trabalho e na vida do trabalhador passem a ser investigados.

Palavras-chave: Toyotismo. Sistema de abastecimento. Trabalho. Trabalhador.

Abstract: This text aims to reflect on the process of productive capital restructuring by the principles of Toyotism and thus present the main impacts on work and labor relations. The Toyotism implements the factory space, the management systems and management of the production process called Just in Time and Kanban. Is adopted as an analytical object to the production line of Mitsubishi Motors automaker of Brazil SA, located in Catalão-GO. Specifically, aims to introduce the principles of Just in Time and Kanban as well as the technical supplies and spare adopted parts on the production line this automaker (andon, supermarkets, sequenced and Kaisen) and also reflect on the impact of these procedures on the labor and employee (multipurpose/multifunctionality, teamwork and outsourcing). In terms of methodology, the text structured by readings and bibliographical researches, compared to observations made during three visits to the area line in this automaker. However, the analyzes presented are guided in theoretical and methodological presupposition of geographical science and aims to contribute to reflections about production model adopted by the automaker as well as their impact at work and the worker's life.

Keywords: Toyotism. Supply system. Work. Worker.

\section{INTRODUC̣ÃO}

A decadência do modelo de produção taylorista/fordista no fim dos anos de 1960 leva a uma nova forma de reorganização da produção e da economia global. É nesse processo de reestruturação produtiva que as forças do capital conseguem introduzir novos métodos e pilares no sistema produtivo, levando o mundo do trabalho a enfrentar novos desafios e problemas com a chegada da acumulação flexível que tem como momento hegemônico o toyotismo, o qual se propaga nos princípios do Just in Time e do Kanban.

A produção fabril passa a adotar procedimentos de abastecimento da linha de produção: andon, supermercado, kaisen, sequenciado, kit/pacote e outros. Com essas novas formas de organização produtiva, há também mudanças no trabalho e nas relações de trabalho devido à adoção da flexibilidade representada por polivalência, trabalho em grupo e terceirização. 
Com base nesses apontamentos, este texto visa contribuir com reflexões acerca do processo de produção desenvolvido na linha de montagem da indústria automotiva Mitsubishi Motors do Brasil S.A. (Mitsubishi ou MMCB), localizada em Catalão-GO, bem como destacar seus impactos no trabalho, nas relações de trabalho e na condição sócio-histórica do trabalhador.

Para alcançar o objetivo proposto, recorre-se metodologicamente às visitas de campo realizadas na montadora no ano de 2009 com o fim de desenvolver a Tese de Doutoramento, intitulada "A indústria automobilística em Catalão/ Goiás: da rede ao circuito espacial da produção da MMC Automotores do Brasil S.A.”. Em termos teóricos, o texto respalda-se nas contribuições de Silva (2011), Santos (2002), Alves (1999, 2007), Franca (2007) entre outros mais, e reporta-se a alguns conceitos importantes para entender a realidade da fábrica toyotizada, dentre eles: toyotismo, reestruturação produtiva do capital e procedimentos de abastecimento de linha de produção.

Para fazer essa reflexão, é preciso dizer que os apontamentos subsequentes referem-se a observações teóricas, associadas ao empírico observado nas visitas à Mitsubishi, nas quais foi possível verificar de forma parcial como se dão as relações de trabalho e como o trabalho é realizado no chão de fábrica.

Portanto, o foco deste texto é reportar-se ao sistema de gerenciamento e gestão da produção automotiva, destacando os processos e etapas que envolvem a montagem veicular, bem como avaliar e analisar os impactos nas relações de trabalho e no cotidiano do trabalhador com a implementação desses novos processos fabris.

\section{UM RELATO SOBRE A MONTADORA MITSUBISHI EM CATALÃO-GO}

A chegada da Mitsubishi em Catalão-GO em 1997 é marcada pela desconcentração industrial e pela reestruturação produtiva do capital automotivo no Brasil, com a criação, por parte do Governo Federal, do Regime Automotivo Especial (Lei n ${ }^{\circ} 9.440$, de 14 de março de 1997), que contribui para a emergência de uma guerra fiscal, promovida pela concessão de incentivos tributários às unidades federadas a qual induz assim à "guerra dos lugares", ou seja, os lugares/municípios passam a disputar entre si a alocação de empresas e, para isso, ofertam benesses fiscais e infraestruturais. É envolta nessa situação de cunho econômico e espacial dos anos de 1990 que a Mitsubishi se instala neste município.

Para fundamentar este recorte temporal, aponta-se alguns elementos que possibilitam o movimento dialético entre a ação do capital e o papel do Estado no processo de implantação e consolidação da MMCB no município goiano. Nesse movimento, encontra-se, de um lado, o capital por intermédio de seus represen- 
tantes, no caso a MMCB; e, de outro, o Estado representado nas hierarquias nacional, estadual e municipal. O poder de decisão, no entanto, cabe mais à empresa capitalista que tem a prerrogativa de escolher a localidade em que irá se instalar.

Com o advento da era informacional, os fluxos possibilitaram um mundo mais rápido, ágil e dinâmico, em que a fluidez se faz presente para a sociedade por meio da circulação de bens materiais e imateriais; dessa forma, transformações imediatas e instantâneas chegam aos lugares e impõem sua carga ideológica capitalista, exigindo uma readequação dos fixos a essa nova realidade. Assim, à medida que o mundo moderno é tecnológica e/ou ideologicamente modificado pelos avanços técnicos e científicos, o sentimento de pertencimento à aldeia global é potencializado nos lugares, fazendo-se presente no cotidiano da população brasileira e goiana, assim como na catalana.

Nesse sentido, os lugares se distinguem segundo a lógica capitalista de que uns podem ganhar mais destaque em relação a outros num processo cuja série de variáveis faz a diferença para sobressair-se no território. A respeito disso, o conhecimento das porções do território torna-se algo imprescindível do ponto de vista do capital, sendo, então, um recurso a serviço do sistema capitalista e de suas representações. Para Santos (2002, p. 242), conhecê-lo é uma premissa importante do ponto de vista do capital:

Pode-se, de um modo geral, dizer que as porções do território assim instrumentalizadas oferecem possibilidades mais amplas de êxito que outras zonas igualmente dotadas de um ponto de vista natural, mas que não dispõem de recursos de conhecimento. Imaginando duas regiões com as mesmas virtualidades físicas, aquela mais bem equipada cientificamente será capaz de oferecer uma melhor relação entre investimento e produto, graças ao just-in-time dos recursos materiais e humanos.

Conhecer os recursos econômicos, educacionais e sociais e saber sobre as potencialidades informacionais, técnicas e tecnológicas de um lugar são elementos fundamentais para o sistema produtivo, pois é com base nesses conhecimentos que grupos empresariais tomam iniciativas de deslocar capitais para este ou aquele lugar. Nesse limiar, Goiás torna-se palco deste tipo de acontecimento, em especial a porção centro-sul, cujos municípios criaram estruturas atrativas (incentivos fiscais) para captar investimentos, com destaque para Rio Verde, Jataí, Anápolis, Itumbiara e Catalão.

No processo de implantação da MMCB em Catalão, as ordens técnica e organizacional, preconizadas por Santos (2002), se fizeram presentes nos esforços empreendidos pelo Estado e também pela própria empresa em busca de rentabilidade: "Os lugares se distinguiram pela diferente capacidade de oferecer rentabilidade aos investimentos. Essa rentabilidade é maior ou menor, em virtude das condições locais de ordem técnica (equipamentos, infraestrutura, acessibilidade) 
e organizacional (leis locais, impostos, relações trabalhistas, tradição laboral)". (SANTOS, 2002, p. 247-248).

Tendo em vista a afirmação de Santos (2002) sobre o processo de instalação e consolidação da montadora em Catalão, chega-se a seguinte análise: as condições locais de ordem técnica, no que diz respeito a infraestrutura, equipamentos e acessibilidade, se destacam: terraplanagem, eletrificação, água e esgoto, sistema de telefonia e internet, jardinagem e vias de acesso à empresa. Todas essas obras foram realizadas pelo Estado, tendo como representantes o estado de Goiás e a Prefeitura Municipal de Catalão (PREFEITURA MUNICIPAL DE CATALÃO/ ESTADO DE GOIÁS/MITSUBISHI, 1997).

A ordem organizacional também é possível ser visualizada no processo de implantação e consolidação da montadora em Goiás, por meio da criação de leis estaduais e municipais, da realização de acordos e assinatura de protocolos, da concessão de incentivos fiscais (abatimento e carência de impostos estaduais e municipais), que foram, e continuam sendo,decisivos para a implantação da montadora, pois a empresa ainda se beneficia das vantagens conquistadas desde 1997, conforme consta no Protocolo de Implantação de Indústria Montadora de Veículos Mitsubishi. Sobre isso Silva (2011) fez análises detalhadas das ações diretas e indiretas empreendidas pelo Estado em suas instâncias federal, estadual e municipal.

É nesse contexto que o processo de consolidação da MMCB vem sendo desenhado a partir deste município-sede desde o lançamento da pedra fundamental de suas instalações industriais, em 06 de junho de 1997, que deu origem à fábrica, inaugurada em 15 de julho de 1998 com a produção da primeira L 200 branca, cabine dupla, motor a diesel e tração nas quatro rodas (PAIVA, 2009; NASSER; SCAVONI, 2010; SILVA, 2002; SILVA, 2011).

Todavia, no período de 2001 a 2003, há a primeira expansão da produção veicular da MMCB, conhecida como Projeto Anhanguera. O Projeto Anhanguera possibilitou a ampliação da capacidade produtiva da montadora com o aumento do número de linhas de produção de duas para três; com o crescimento do número de vagas empregatícias ofertadas; com a ampliação da área construída de 14 mil $\mathrm{m}^{2}$ para $57 \mathrm{mil} \mathrm{m} \mathrm{m}^{2}$ e com a duplicação da capacidade de produção da fábrica que passou de 15 mil unidades por ano para 28 mil (MMCB, 2015).

Muito se falou, e muito ainda se fala, sobre a chegada e a permanência da empresa em Catalão, mas a realidade é que a empresa completou 18 anos de operação no município, apesar das crises das economias mundial e brasileira, e aponta para a expansão da planta industrial e da produção nos próximos anos.

A Tabela 1 traz dados levantados inicialmente por Silva (2011, p. 357), complementados e atualizados para as análises a seguir. 
Tabela 1. Quantidade de veículos licenciados pela MMCB: 1999 a agosto/2015

\begin{tabular}{cc}
\hline Ano & Produção de automóveis e comerciais leves \\
\hline $1999^{*}$ & 3.098 \\
2000 & 6.252 \\
2001 & 8.571 \\
$2002^{* *}$ & 9.743 \\
2003 & 11.767 \\
2004 & 18.011 \\
2005 & 20.153 \\
2006 & 20.171 \\
$2007^{* *}$ & 22.464 \\
2008 & 37.203 \\
2009 & 32.429 \\
2010 & 59.640 \\
2011 & 55.533 \\
2012 & 60.577 \\
2013 & 58.174 \\
2014 & 59.280 \\
Ago/15 & 21.220 \\
Total da Produção & 504.286 \\
\hline
\end{tabular}

Fonte: adaptada de Silva (2011) e Anfavea (2015).

* A ANFAVEA não disponibilizou a produção de 1998 via site oficial.

* * A partir de junho/2002 a Mitsubishi inicia a montar a Pajero TR4 a gasolina. Em junho de 2007 inicia-se a produção da L200 flex.

Os dados da tabela mostram que a produção de veículos da montadora vem crescendo desde sua instalação em Catalão. Em 2009, nota-se uma queda na produção devido à crise da economia mundial que se iniciou em 2008 e afetou o mercado automotivo nacional, mas no ano seguinte, 2010, a empresa começa a montar um novo modelo de veículo (ASX) e alavanca as vendas automotivas no mercado nacional e internacional. Já em 2014, com uma nova expansão, denominada de Projeto Anhanguera II, a fábrica começa a produzir o sedan Lancer (MMCB, 2015).

De acordo com os dados da produção total de 2014, constata-se que a empresa produz diariamente cerca de cento e sessenta veículos, dentre eles: Lancer, Pajero, L200 Triton e suas versões e ASX. Além disso, a empresa importa os ve- 
ículos Pajero Full, Outlander e Lancer Evolution X que passam por um processo de nacionalização antes de serem distribuídos para o Brasil por meio de concessionárias autorizadas.

O processo de consolidação da produção automotiva em Catalão envolve relações diversas da montadora com fornecedores, empresas prestadoras de serviços, consultorias, terceirizadas e concessionárias autorizadas, os quais mediante ações isoladas e conjuntas organizam um circuito espacial da produção com alcance multiescalar (local, regional, nacional e internacional). Para maiores informações recorrer a Silva (2011).

Entretanto, parte da concepção e do desenvolvimento produtivo destes veículos se dá nesta fábrica em Catalão, cujas etapas envolvem P\&D, projetos, montagem, testes de qualidade e auditoria final, gestadas de forma a garantir a eficácia na produção e a distribuição dos veículos. Para isso, usa-se das premissas da ciência, da tecnologia e do mercado. A respeito disso, tratar-se-á na seção subsequente.

\section{REESTRUTURAC̣ÃO PRODUTIVA E TOYOTISMO}

A decadência do modelo de produção fordista/taylorista, no fim dos anos de 1960 e no início dos anos de 1970, é marcada principalmente pela rigidez da produção fordista, cujos princípios da produção em massa e em série se mostraram incapazes de responder à retração do consumo em massa.

Para Antunes (2009), alguns fatores contribuíram para tal decadência, dentre eles: aumento do desemprego, diminuição dos investimentos públicos e privados na indústria, eclosão de revoltas e ações ofensivas do operariado, internacionalização do capital e rigidez da produção fordista para acompanhar as inovações técnicas e tecnológicas. Esses fatores permitiram que o capital se reinventasse sobre bases tradicionais, mas com uma nova proposta de reprodução e reorganização produtiva baseada em inovações tecnológicas.

Essa nova forma de reorganizar a produção é imposta à economia global por meio da globalização que gera a mundialização do capital, em que ocorre a predominância de um regime de acumulação financeira, conforme aponta Chesnais (1996), porém, não atinge homogeneamente os lugares.

$\mathrm{O}$ processo de reestruturação das bases produtivas durante o século XX fez com que as forças do capital conseguissem introduzir novos métodos de produção e de trabalho. Iniciou-se com o padrão taylorista/fordista e vem até a fase denominada de acumulação flexível, em que o sistema capitalista passa a operar sob bases mais flexíveis, como a representada pelo Toyotismo. A respeito disso, Alves (1999, p. 13, grifos do autor) afirma que: “A passagem do fordismo para a acu- 
mulação flexível implica em transformações sociopolíticas (e culturais) relevantes que atingem os vários mecanismos de regulação social e política das múltiplas contradições que permeiam os possuidores de capital e, principalmente, entre os capitalistas e os trabalhadores assalariados".

O capitalismo mundial, a partir de 1970, é atingido por um complexo de inovações sociais, políticas, tecnológicas e culturais que trazem modificações radicais aos processos de trabalho, aos hábitos e às formas de consumo, às configurações geográficas e geopolíticas, aos poderes e às práticas do Estado, entre outros, e, dessa forma, inaugura um novo período histórico pautado pela reestruturação produtiva, que surge no interior da revolução tecnológica, envolvendo a microeletrônica e as redes telemáticas e informacionais, com impactos na constituição do mundo do trabalho que se torna cada vez mais precarizado.

Essas novas formas de ações da produção capitalista-industrial estão traçadas no Toyotismo que configura-se como mais um elemento do longo processo de racionalização da produção capitalista e de manipulação do trabalho vivo originado com o taylorismo/fordismo.

Para Alves (2007, p. 156), o Toyotismo torna-se "o verdadeiro espírito do novo complexo de reestruturação produtiva, a ideologia orgânica da produção capitalista sob a mundialização do capital”. Ainda afirma que:

[...] o novo complexo de reestruturação produtiva trata de inovações sociais interiores e inovações exteriores à produção capitalista. [...] nas inovações interiores à produção capitalista, destacando as inovações organizacionais (o toyotismo é, a princípio, uma inovação organizacional, [...]); as inovações tecnológicas (as novas tecnologias microeletrônicas de produção e as novas tecnologias telemáticas, informacionais e em rede); e as inovações sociometabólicas (um aspecto do processo de reestruturação produtiva pouco destacado pela sociologia do trabalho, mas que, com o toyotismo e sua ânsia pela "captura" da subjetividade, tende a assumir uma dimensão crucial). (ALVES, 2007, p. 156).

É nesse sentido que o Toyotismo, como inovação organizacional, torna-se algo importante no processo produtivo, pois centraliza as ações no espaço fabril pela imposição estratégica de seus protocolos organizacionais e institucionais, que impactam as condições de trabalho e o ritmo do trabalho. O Toyotismo ou Sistema Toyota de Produção (STP), desenvolvido no início dos anos de 1950 na fábrica da Toyota Motors Company, no Japão pelo engenheiro Taiichi Ohno, ganha dimensão universal pós-1980 juntamente com a mundialização do capital e o processo de acumulação flexível, sob a forma da lean production (produção enxuta), cujo objetivo principal é aumentar a produtividade.

Dessa forma, os princípios do Toyotismo baseados em valores e regras de gestão do trabalho, concatenados com procedimentos técnico-organizacionais, 
atingem os empreendimentos capitalistas, seja na indústria, no comércio ou nos serviços. Portanto, é sobre esses procedimentos técnico-organizacionais deixados pelo Toyotismo que se trata a seguir.

\subsection{Considerações sobre o Kanban e Just in Time}

O Toyotismo, imbuído de procedimentos técnico-organizacionais, usa de tecnologias diversas no sistema de produção, com o fim de agilizar etapas e fases produtivas, diminuir desperdícios e prejuízos, evitar grandes volumes de capital imobilizado, fabricar produtos de qualidade e outros medidas passam a fazer parte desse novo complexo produtivo, em prol do aumento da lucratividade e da produtividade.

Nesse intento, as primeiras ondas de ações empreendidas no espaço da fábrica pelo Toyotismo foram a dos CCQ's e, quase que em paralelo, a do Kanban/ Just in Time (JIT). Posteriormente, diversos outros elementos foram adicionados, como TQC (Total Quality Control), Kaizen, técnica dos 5S's, TPM (Total Productive Maintenance) e outras. (ZILBOVICIUS, 1997 apud ALVES, 2007, p. 160, destaques do autor).

É com base nesse conjunto de ações que envolve o uso intensivo das possibilidades da Tecnologias da Informação (TI's) que o Toyotismo passa a operar com base no Kanban mediado pelo JIT. O Kanban (significa "cartão" em japonês) é uma técnica de produção idealizada por Taiichi Ohno com o objetivo de agilizar o fluxo de informações no interior das empresas. Segundo Malaguti (1996, p. 48), Ohno:

[...] concentrou seus esforços na criação de um sistema (Kanban) que pudesse determinar, de forma precisa, a quantidade de mercadorias efetivamente vendidas e que, ao mesmo tempo, pudesse fazer chegar essa informação aos postos de trabalho que as confeccionam. Assim fazendo, rompeu com a arraigada tradição fordista da primazia da produção sobre o consumo, transformando o consumo no verdadeiro impulsionador da produção: em lugar de produzir para um mercado incerto, o sistema criado por Ohno detecta as exigências do mercado e só permite a produção do que já está - quase ou literalmente - vendido.

Foi com base na possibilidade de determinar a produção conforme as exigências do mercado/demanda e na premissa flexível do JIT e das TI's que o primeiro passou a ser adotado especialmente na indústria. Por JIT, Heckert e Francischini (2015, p. 1) entendem que:

O Just-in-Time (JIT) é um modelo de gestão da produção, em que os insumos são fornecidos apenas no momento em que serão processados. Este sistema veio substituir o Just-in-Case, no qual grandes quantidades de materiais e produtos ficavam estocados para estarem disponíveis quando fossem necessários ao processo produtivo. 
O principal objetivo do JIT é a diminuição dos estoques e a consequente redução de custos, pois, com ele, torna-se necessária menos área disponibilizada e menor capital empatado.

Ainda, este modelo produtivo enfatiza a gerência no fluxo de produção, procurando fazer com que os produtos fluam de forma suave e contínua pelas diversas fases do processo produtivo, ou seja, “a implantação de um sistema de produção JIT requer uma grande flexibilidade na programação da linha de produção e, acima de tudo, uma ótima sincronia de trabalho entre cliente e fornecedores" (HECKERT; FRANCISCHINI, 2015, p. 2).

Considerando que a ênfase prioritária do JIT para as linhas de produção é a flexibilidade, isto é, espera-se que as linhas de produção sejam balanceadas para que a produção esteja ajustada às variações da demanda, isso possibilita uma maior integração entre funcionários e poucas ocorrências que levem a desperdícios ou atrasos no processo produtivo. Assim, ocorre o aproveitamento total do tempo em detrimento de um maior controle da força de trabalho.

Com a implantação dos princípios do Toyotismo pelo Kanban e pelo Just in Time, o sistema de produção industrial passou por processos de transformações com implicações diretas para o modo de produzir e também para o modo de administrar todo o circuito produtivo. Com base nas técnicas do Kanban e JIT, as empresas tornam-se mais enxutas, eliminando os desperdícios para obter mais vantagens competitivas.

Portanto, é a partir dessas bases que o JIT ganha caráter universal no pós1980 e se espacializa com a implantação na produção de seus princípios flexíveis, portanto, com impactos sobre o trabalho e o trabalhador.

Para Abramides e Cabral (2003, p. 4), “A acumulação flexível, com o Toyotismo, torna-se para o capital tanto uma forma de maior exploração quanto de maior controle sobre a força de trabalho", ou seja, com a implantação dos princípios do Toyotismo pelo Kanban e pelo JIT, o controle e o domínio sobre a produção, o trabalho e o trabalhador tornam-se essenciais para a reprodução do capital.

Ainda, o Kanban surgiu inspirado no funcionamento de supermercados norte-americanos que em alguns aspectos chamou a atenção de Taiichi Ohno, pai intelectual do Toyotismo, dentre eles: a disposição de mercadorias em prateleiras, informações importantes codificadas em um pequeno cartão; a mercadoria é retirada pelo próprio consumidor e sua reposição é feita de acordo com a demanda (ANTUNES, 2009; ALVES, 1999).

Com base nessas características observadas nos supermercados, começou-se a adotar o Kanban nas montadoras com as devidas adequações. Assim, com esse sistema não se produz nada até que o cliente (interno ou externo) solicite a produção (DAL FORNO; TUBINO; VALLE, 2007). 
Considerando que o Kanban implementa uma produção orientada e conduzida pela demanda do mercado de consumo, em complementação a esse pressuposto o JIT torna-se um modelo de gestão produtiva, pois os insumos são fornecidos apenas no momento em que serão processados, ou seja, a ideia de produção enxuta passa a imperar na indústria, no comércio e nos serviços, cujos desdobramentos nos processos produtivos e no trabalho são notáveis.

As transformações no sistema de produção industrial são sentidas no modo de produzir e de administrar a cadeia produtiva. Dessa forma, aumento de produtividade, estoques mínimos, produção enxuta, eficiência, qualidade, novas formas de uso da tecnologia e de gestão são efetivadas por meio de inovações tecnológicas e de protocolos organizacionais aplicados ao espaço fabril. Ressalta-se que tais ações foram observadas nos procedimentos produtivos adotados pela montadora Mitsubishi.

As empresas baseadas nas técnicas do JIT tornam-se mais enxutas, eliminando os desperdícios em prol de competitividade e da redução de capital imobilizado, e passam a adotar procedimentos de abastecimentos na linha de produção, tais como: andon, kaisen, supermercados, CCQ, kit/pacote e sequenciado. A adoção da polivalência, do trabalho em grupo e da terceirização configuram flexibilização produtiva e tem consequências na precarização do trabalho e na condição social do trabalhador (FRANCA, 2007). Estes últimos procedimentos serão analisadas a seguir, conforme realidade verificada mediante trabalhos de campo realizados na linha de produção da MMCB.

Nota-se que com a mudança do modelo de produção fabril fordista/taylorista para o toyotista, alguns elementos ainda se mantêm e continuam a conduzir a produção, dentre eles: esteira, reprodução do capital, precarização do trabalho, sujeição do trabalhador às imposições do capital.

A esteira, tanto na produção fordista quanto na toyotista, permite a articulação de diferentes etapas de produção, além de dar ritmo e tempo necessários para a realização das tarefas pelos trabalhadores, conforme ajustes de velocidade. Sobre isso, nota-se que o ritmo da produção não é ditada pela capacidade de desempenho laboral do trabalhador, mas pela programação da velocidade da esteira, que traz em si elementos que induzem a reprodução do capital e a precarização do trabalho.

O JIT associa-se ao Kanban e vice-versa. O Kanban perfaz "[...] um sistema de programação da produção puxada para atender as necessidades dos clientes e facilitar o gerenciamento visual da fábrica" (DAL FORNO, TUBINO, VALLE, 2007 , p. 2). O JIT torna-se a técnica de gestão e gerenciamento da produção e do processo produtivo de forma a efetivar e implementar o Kanban.

Em outras palavras, no Kanban a produção volta-se para atender a demanda do mercado consumidor (produção puxada), atuando em consonância com 
a ideia de produção enxuta e eliminando grandes estoques de produtos industrializados. Dessa forma, a produção puxada é entendida como "um sistema de produção em que cada etapa do processo só deve produzir um bem ou serviço quando um processo posterior ou cliente final o solicite". (DAL FORNO; TUBINO; VALLE, 2007, p. 3). Assim, o JIT mediante uso de TI's só vai programar a produção conforme determinação do Kanban.

Dessa forma, a produção atua diretamente associada ao sistema de controle e gestão de estoques. A programação da produção mantém um sistema de planejamento eficaz para evitar desperdícios ou prejuízos financeiros, como: deixar produtos estocados por muito tempo sem usá-los na produção e/ou estocar produtos industrializados sem venda programada - e, ainda, atentar para que não falte componentes na linha de montagem.

Nota-se que o Kanban e o JIT são sistemas de gestão de produção que usam inovações tecnológicas para realizar ajustes entre trabalhador e equipamentos com o fim de aumentar a produtividade e maximizar os lucros, porém, o impacto nas relações de trabalho tem sido pouco pesquisado. Nesse caso, um dos impedimentos está na condição imperativa do capital de camuflar a realidade do chão de fábrica e desqualificar as lutas sociais por condições melhores de trabalho.

Portanto, para aprofundar a reflexão sobre as técnicas de abastecimento usadas pelo JIT no espaço fabril, na sequência, far-se-á uma abordagem de como estas são aplicadas à linha de produção da montadora automotiva Mitsubishi, de acordo com elementos e aspectos observados em trabalhos de campo realizados no ano de 2009.

\subsection{O uso das técnicas de abastecimento do JIT na linha de produção da Mitsubishi, em Catalão-GO}

Conforme aponta Franca (2007) e Alves (2007), para que o JIT fosse de fato implantado no chão de fábrica, as empresas passaram a adotar procedimentos de abastecimentos da linha de produção, tais como: andon, kaisen, supermercados, CCQ, kit/pacote e sequenciado.

No caso da MMCB, isso foi registrado em três visitas in loco realizadas em 2009 por meio de observações e conversas gravadas com o funcionário-guia José Douglas Amorim - para fins de pesquisa de campo para Tese de Doutorado intitulada $A$ indústria automobilística em Catalão/Goiás: da rede ao circuito espacial da produção da MMC Automotores do Brasil S.A.

A partir dessas visitas de campo, notou-se a existência de três linhas em que se montam modelos de veículos diferentes, entre eles: L200 Triton, L200 Outdoor, Pajero TR4 Flex, ASX e, mais recentemente, Lancer. Para tanto, os ajustes necessários para a montagem de veículos diferentes, nestas linhas de produção, 
requerem o uso de um conjunto de inovações tecnológicas e de protocolos organizacionais que chegam à fábrica pelo uso do Kanban e do JIT, sendo organizadas conforme os procedimentos de abastecimento da linha de produção.

Ressalta-se que todo o processo, incluindo o desenvolvimento de tecnologias, produtos, ferramentais, aquisição de produtos, montagens em diversas etapas da produção e distribuição, é organizado pela montadora, cujas relações com seus parceiros são variadas, pois abrangem fornecedores, prestadores de serviços e terceirizados, transportadoras, concessionárias e outras. Portanto, nesse processo, o PeopleSoft - software que auxilia na gestão da produção - assume papel relevante, pois, sem esse software, a montadora se perderia na burocracia e nas milhares de tarefas exigidas para a produção veicular. O objetivo do software é exatamente agilizar e organizar as ordens e as etapas a serem cumpridas em prazos estipulados para os setores da fábrica pelos comandos virtuais.

Considerando os pressupostos básicos do JIT e as observações empíricas realizadas a partir das três visitas à linha de produção da montadora da MMCB, verificou-se que a referida indústria adota um modelo de gerenciamento e organização da produção automotiva baseado no Kanban e JIT. No Kanban, porque produz conforme demanda do mercado (produção puxada) e no JIT, porque utiliza inovações tecnológicas na gestão de todas as etapas do processo produtivo.

Observou-se também que a montadora mescla, no processo produtivo, padrões oriundos do taylorismo/fordismo com inovações do Toyotismo.

De acordo com esse novo modelo de produção, para que o fluxo de abastecimento da linha de montagem não seja interrompido por falta de componentes - job stop -, é necessário que o sistema JIT, em cumprimento ao que determina o Kanban, adote técnicas complementares de abastecimento. No caso da montadora Mitsubishi, verificou-se que algumas técnicas são adotadas em sua linha de produção e no controle de estoque, entre elas: supermercado, andon, sequenciado e kaizen.

$\mathrm{Na}$ Mitsubishi, os Supermercados estão presentes na linha de produção e são representados por marfinite (prateleiras ou contêineres) onde ficam armazenadas peças de pequeno porte, como: parafusos, fiação, acessórios etc. Porém, cabe esclarecer que os supermercados são pontos de armazenamento (prateleiras/ contêineres) que acompanham a linha de montagem com peças comuns a um determinado modelo de veículo.

Segundo Franca (2007, p. 45), o supermercado: "É um sistema para abastecer itens em um ponto centralizado, geralmente de difícil acesso". O controle do estoque de componentes nas prateleiras/contêineres se dá pelos cartões Kanban. Em cada supermercado, há um painel porta-kanban (cartão magnético), que é acionado eletronicamente pelo funcionário multifuncional, informando assim ao estoque a necessidade de enviar componentes para reabastecer os contêineres. 
No caso da montadora Mitsubishi, o funcionário multifuncional retira o cartão magnético (espécie de adesivo com código de barras) da peça limite que está no marfinite (prateleira/contêiner), onde se mantém um estoque mínimo. Este cartão é recolhido pelo pessoal de materiais (abastecedor), que circula pela linha de produção, com tempo de passagem a cada dez minutos. O abastecedor comunica pelo coletor (scanner que faz leitura do código de barras do cartão magnético) a falta de peças. O pedido de novas peças é processado no estoque e, dentro de alguns minutos, um carrinho reboque busca as peças faltosas para o multifuncional completar o marfinite.

A técnica porta-kanban parte do princípio de que o abastecimento da linha de montagem com componentes é proveniente do estoque, ou seja, o uso destes cartões serve para comunicar a falta de determinado produto na linha de produção e, dessa maneira, o procedimento de reabastecimento é repetido diversas vezes durante a operação da linha de produção. Assim, a reposição nos supermercados deve seguir o que Dal Forno, Tubino e Valle (2007, p. 3) afirmam: "O processo fornecedor precisa repor o supermercado antes que os níveis mínimos de peças definidos sejam atingidos". No entanto, a reposição dos supermercados depende do quantitativo de material armazenado no estoque geral da montadora.

Com base nessas informações, o abastecimento dos supermercados se dá associado ao uso da técnica porta-kanban, procedimento padrão usado em diversas montadoras. Porém, o abastecedor pode ter problemas ao desenvolver suas atividades laborais, entre os mais comuns estão: atrasar o abastecimento devido à dificuldade de encontrar determinados itens e produtos no estoque; falta de peças no estoque; rejeição de peças devido a problemas de fabricação (qualidade); cartão disparado em momento errado; a peça não possuir o cartão; cartão não ser disparado etc. (KIYOHARA, ALMEIDA, 2004). Ficando a responsabilidade dos atrasos na linha de produção para o trabalhador.

Outro procedimento de reposição de peças na linha de produção da Mitsubishi é o andon. É uma técnica que atua pela emissão de sinais eletrônicos capazes de informar a falta de um componente na linha de produção. Este procedimento tem como propósito o abastecimento de peças grandes e necessita do uso de empilhadeiras ou carrinhos (FRANCA, 2007).

O andon é conhecido na Mitsubishi como Chamada Direta. Esta técnica usa um coletor que envia automaticamente a falta de componentes ao SMART (estoque de itens/componentes volumosos), em seguida é realizada a reposição do produto. Entre os tipos de itens grandes usados pela montadora e que estão mais propensos à paradas na produção,estão: radiadores, escapamentos, pneus e para-choques. Como se trata de componentes de grande porte, não há espaço físico, ao lado da linha de montagem, para armazenar uma maior quantidade, por isso o abastecimento é sequenciado. 
Além dessa função, a Chamada Direta assume papel fundamental no processo de gestão e gerenciamento da linha de montagem, por ser um sistema de alerta de job stop, que pode se dá pelo acionamento de sensores eletrônicos instalados ao longo da linha de produção e/ou de um painel eletrônico visível para toda a fábrica.

Esses sensores servem para avisar a falta de abastecimento de componentes com maior chance de parar o funcionamento da produção. Dessa maneira, com o acionamento do painel de alerta da Chamada Direta, ainda é possível que os operadores resolvam o problema de abastecimento antes de acionar sinal vermelho com a consequente parada da montagem veicular.

Ainda concernente às técnicas de abastecimento da linha de produção da montadora, nota-se que ela adota o procedimento sequenciado, que se refere ao abastecimento em sequência de diversas peças oriundas do estoque (FRANCA, 2007). $\mathrm{Na}$ Mitsubishi esse procedimento é denominado de Chamada Direta Sequenciada.

Segundo Heckert e Francischini (2009, p. 3), o abastecimento sequenciado também é denominado de Just in Time Sequenciado (JITS), isto é,

[...] as peças são entregues pelo fornecedor diretamente na linha de montagem da montadora, já na sequência em que serão colocadas nos automóveis. Este tipo de fornecimento é considerado como o de melhor relação benefício-custo de implantação. Com o JITS as entregas tornam-se mais frequentes ainda, em lotes cada vez menores (geralmente o suficiente para cerca de duas horas de produção) (HECKERT; FRANCISCHINI, 2015, p. 3).

A Chamada Direta Sequenciada na MMCB está representada pelo abastecimento de conjuntos de rodas/pneus e de componentes plásticos (para-choques, para-lamas, proteção de carrocerias), cujas entregas são realizadas diretamente pelos fornecedores. Para tal, as empresas fornecedoras do conjunto de roda/ pneu - Fórmula R Indústria - e de componentes plásticos - MVC Componentes Plásticos - possuem funcionários que os levam até a linha de produção para serem devidamente montados. Esse abastecimento obedece à programação diária de produção de veículos por parte da montadora, conforme quantidade e controle por número de chassi e modelos (SILVA, 2011).

Ressalta-se que a adoção da Chamada Direta Sequenciada requer confiança na parceria entre montadora e empresas fornecedoras. Nesse caso, o fato dos fornecedores estarem alocados nas proximidades da montadora ou dentro de sua área industrial facilita o fornecimento destes produtos, que pode ser realizado diversas vezes por dia, além disso, reduz custos com transportes, e ainda outros problemas podem ser solucionados rapidamente e de forma pessoal.

A busca de soluções de problemas surgidos na linha de montagem é conhecida como Kaizen. Esse procedimento, que é bastante comum na MMCB, fica a 
cargo dos multifuncionais, encarregados de processos e supervisores de produção. Estes ao se depararem com algumas dificuldades na produção, inconformidades em peças e serviços, problemas técnicos e de atrasos na linha de produção, passam a atuar em equipe para buscar soluções, ou seja, são os funcionários que precisam resolver ou indicar os caminhos certos para evitar atrasos na montagem veicular e prejuízos financeiros à empresa.

O kaisen exige dos trabalhadores citados um conhecimento profundo das técnicas de abastecimento adotadas na montadora, pois eles precisam apontar soluções para os problemas que surgem, e ainda induz o envolvimento do trabalhador com a produção, levando-o a ser responsável não apenas pela montagem veicular, mas também pelo bom funcionamento da fábrica para atender a tempo a demanda do mercado.

É importante frisar que compreender as formas de abastecimento de uma linha de montagem automotiva requer estudos minuciosos e conhecimento de como ela funciona e se mantém em operação, no entanto, todas as técnicas usadas na linha de montagem são complexas e exigem o que os trabalhadores, além de serem responsáveis pela montagem, também estejam envolvidos na busca de soluções para possíveis problemas.

As técnicas de abastecimentos troca de equipamentos (emissão de sinais eletrônicos de carrinho vazio para informar a falta de componentes) e kit/pacote (o número de unidades produzidas indica a necessidade de reposição de um conjunto de componentes) não foram detectadas nesta montadora, sendo necessária uma pesquisa mais aprofundada para verificação (FRANCA, 2007).

Ainda destaca-se que a implementação do JIT e das técnicas usadas na montagem veicular da Mitsubishi (andon, supermercados, sequenciado e kaizen) tratadas neste texto não garantem o pleno funcionamento, por isso a empresa adota outras ações complementares na produção que necessitam de pesquisas mais detalhadas.

Entretanto, para as técnicas relatadas funcionarem de forma eficaz, estas se associam à adoção da polivalência/multifuncionalidade, do trabalho em grupo/ em equipe e da terceirização, que configuram uma flexibilização produtiva e a precarização do trabalho e da condição social do trabalhador (FRANCA, 2007).

Contudo, com base nas informações relatadas, nota-se que a produção na MMCB está integrada à demanda do mercado, exigindo um controle de qualidade e planejamento rigoroso para que as ações e medidas sejam eficazes durante a operação da linha. E ainda que a empresa monta veículos diariamente conforme a demanda do mercado consumidor (informada pelas concessionárias), ou seja, usa-se o sistema Kanban. Se de um lado, o mercado determina a produção, por outro, ele também determina o ritmo e tempo de trabalho dos trabalhadores. É sobre essas determinações que se propõe a discussão a seguir. 


\section{KANBAN E JIT E OS IMPACTOS NAS RELAC̣ÕES DE TRABALHO NA MITSUBISHI: ALGUNS APONTAMENTOS}

O uso dos sistemas Kanban e JIT com suas diversas técnicas de abastecimento da linha de produção fabril associados ao trabalho polivalente/multifuncional, ao trabalho em grupo e à terceirização permitem configurar a flexibilização produtiva, elevando a produção conforme a necessidade da produção puxada, mas com impactos nas relações de trabalho e na condição sócio-histórica do trabalhador.

Para fazer essa reflexão, é preciso dizer que os apontamentos subsequentes referem-se a observações teóricas, associadas ao empírico constatado nas visitas à Mitsubishi, onde foi possível verificar de forma parcial como se dão as relações de trabalho no chão de fábrica.

Sobre essa associação entre modelo de gestão organizacional da produção, procedimentos produtivos e trabalho, é preciso destacar que, com a revolução técnico-científica, os elos entre a máquina e a informática são aprimorados sistematicamente, resultando no aumento da automação, na elevação da produtividade, nos ganhos em qualidade dos produtos postos no mercado consumidor, na redução de vagas de trabalho e na exigência de um trabalhador cada vez mais apto a aderir e a absorver laboralmente esse novo complexo de produção.

Reconhece-se que as tecnologias informacionais são indispensáveis para o desenvolvimento do sistema de gerenciamento da produção JIT, cuja gestão contribui para manter a continuidade e aceleramento da produção e permite controlar os processos produtivos tanto dentro como fora da fábrica. Além disso, o JIT permitiu ainda mais o controle sobre os meios de trabalho e o domínio sobre o trabalhador, levando a um processo de precarização do trabalho.

Sobre a precarização do trabalho e a constituição do precário mundo do trabalho, Alves (2007) faz a seguinte consideração:

[...] o processo de precarização do trabalho e a constituição do precário mundo do trabalho são traços do novo sociometabolismo do capital nas condições da mundialização financeira. Ela atinge tanto países capitalistas centrais, como países capitalistas periféricos, como o Brasil. Inclusive, no caso do capitalismo brasileiro, o processo de precarização do trabalho assume dimensões complexas, articulando tanto dimensões histórico-genéticas (originárias da nossa formação colonial), quanto dimensões histórico-sociais vinculadas à nova ordem da mundialização do capital (ALVES, 2007, p. 111, grifo do autor).

Com a nova ordem imposta pela mundialização do capital industrial e financeiro ao processo produtivo observa-se que as dimensões sociais do trabalho assumem um novo patamar, marcado pela intensificação das atividades laborais 
no espaço fabril que assume um caráter flexível, desigual e precarizado. Para Alves (2007, p. 115, grifo do autor): “A precarização atinge os proletários sujeitos de direitos e que hoje são vítimas da 'flexibilização do trabalho', sendo usurpados pelo poder das coisas ou pelas leis de mercado". Dessa forma, direitos trabalhistas são usurpados ou descumpridos em nome da rentabilidade financeira do capital produtivo.

Continuando a reflexão, nota-se que com a efetivação do Kanban e do JIT no espaço fabril, o capital busca meios e alternativas para retomar a acumulação mediante a implantação de novas formas de gestão, controle do trabalho e ampliação da exploração da força de trabalho, que se dá pela mais-valia relativa, caracterizada pelo uso da inovação tecnológica, e também pela mais-valia absoluta, representada pela ampliação do ritmo de trabalho, levando a "subsunção real do trabalho ao capital", devido ao uso de máquinas na produção fabril (ANTUNES, 2009, p. 39). Assim, o trabalhador é submetido ao que dita o mercado por meio da produção puxada.

Nesse viés, é importante destacar que as técnicas de abastecimento e reposição de peças na linha de produção automotiva associadas ao uso de inovações técnica e organizacional no processo de trabalho diminui a porosidade, isto é, permite «reduzir o tempo de transporte de um produto ou informações entre uma operação e outra no espaço da fábrica" (FRANCA, 2007, p. 46-47), em outras palavras, significa redução das barreiras espaciais entre as escalas geográficas dentro e fora da fábrica. Compreendendo o estudo de Silva (2011), essa redução de tempo e eliminação de barreiras espaciais vai além do chão de fábrica e abrange o circuito espacial da produção da montadora em estudo.

Ainda, a redução do tempo entre as etapas da produção, bem como a eliminação de algumas fases no processo produtivo, representa a "exclusão de trabalhadores", cuja tarefa passa a ser realizada por um número reduzido de trabalhadores ou por robôs (FRANCA, 2007, p. 48).

Isso significa que o sistema JIT desenvolveu-se como força antagônica aos trabalhadores, pois a automação e o controle das atividades produtivas levam o trabalhador a aumentar seu esforço físico e psicológico para desempenhar tarefas de forma condensadas e múltiplas, pois a eminência da demissão está presente em seu dia a dia. Além disso, o trabalhador convive com o estresse cotidiano no chão de fábrica, pois desempenha suas atividades conforme a programação e a rotatividade de trabalhadores no chão de fábrica.

A respeito dessa rotatividade de trabalhadores e da redução de trabalhadores nesta montadora, destaca-se que, de janeiro a início de outubro de 2015, houve demissão em massa por duas vezes: a primeira se deu em julho com o desligamento de 179 funcionários em um só dia, e a segunda ocorreu no dia 2 de outubro de 
2015 com demissão de cerca de seiscentos trabalhadores (PORTAL CATALÃO, $2015 \mathrm{a} ; 2015 \mathrm{~b})$. Além da rotatividade contínua, recentemente os trabalhadores passaram a conviver com demissões em massa, fatos que causam estresse e pressão psicológica, pois eles podem ser demitidos a qualquer momento. Tais ações por parte da empresa têm gerado mobilizações dos trabalhadores em busca de alternativas e de acordos, mas eles têm obtido pouco êxito devido à rigidez patronal nas decisões de enxugamento de funcionários a fim de manter os lucros previstos, mesmo em período de crise da economia mundial.

Ainda, em outras palavras, o JIT ampliou o controle do trabalho e sobre o trabalhador, tornando o processo produtivo ininterrupto (sem paradas) ao eliminar as porosidades e exigir cada vez mais um trabalhador atento ao exercício de suas atividades, que recrie valor e lucro e realize um trabalho produtivo.

Nesse sentido, Antunes (2009, p. 54-55, grifo do autor) complementa dizendo que na fábrica toyotizada utiliza-se de técnicas de gestão do trabalho, que, na verdade,

[...] trata-se de um processo de organização do trabalho cuja finalidade essencial, real, é a intensificação das condições de exploração da força de trabalho, reduzindo muito ou eliminando o trabalho improdutivo, que não cria valor, quanto suas formas assemelhadas, e inspeção de qualidade, funções que passaram a ser diretamente incorporadas ao trabalhador produtivo.

O Toyotismo com o JIT adota uma organização da produção que traz uma nova intensificação do trabalho, por meio da "desespecialização dos trabalhadores qualificados”, da instalação de uma certa polivalência e plurifuncionalidade dos homens e das máquinas, e ainda do "tempo partilhado", baseado em tarefas múltiplas, em padrões (de tempo e de trabalho) flexíveis (ALVES, 1999, p. 111).

A polivalência torna-se "uma possibilidade produtiva vantajosa para a empresa” (FRANCA, 2007, p. 50). Imbuída desse preceito, a MMCB adota o trabalhador polivalente, conhecido como multifuncional, cuja atividade é controlar uma célula de produção na linha de montagem, ficando sob sua responsabilidade a qualidade do processo produtivo e a eficácia das tarefas executadas pelos trabalhadores desta célula. Na configuração atual da linha de montagem desta empresa, o trabalhador multifuncional é um líder no processo produtivo. Nesse viés, o trabalhador multifuncional desempenha várias atividades ao mesmo tempo, portanto, mantém-se em estado de trabalho permanente, exigindo-lhe um esforço físico e mental constante. Sobre isso, Alves (2007) chama a atenção:

Na verdade, no sistema do capital, a politecnia interverte-se em polivalência. Novas habilidades cognitivas e comportamentais exigidas pelo toyotismo apenas repõem a situação de estranhamento e de alienação humano-genérica. O trabalho árduo não é 
abolido. Pelo contrário, surgem novas formas de intensificação de trabalho com impactos perversos na estrutura psíquica (e mental) de homens e mulheres trabalhadoras, como demonstram as novas empresas toyotizadas e o contingente de operários e empregados estressados. O que significa que o desenvolvimento do toyotismo, com suas novas habilidades cognitivas e comportamentais, contribui para a disseminação de uma nova psicopatologia do trabalho, com o crescimento de doenças psicossomáticas ou ainda, "doenças da alma”, expressão de uma subjetividade visada pelo capital. (ALVES, 2007, p. 254, grifos do autor).

A empresa em análise utiliza ainda o trabalho em grupo, geralmente sob o comando do trabalhador multifuncional. No trabalho em grupo ou em equipe é disseminada uma ideologia voltada para a eficiência e a necessidade de cooperação no trabalho, em que o espírito de compromisso e solidariedade é permanente, pois a produção precisa ser cumprida no tempo certo e com a qualidade exigida (FRANCA, 2007).

Essa captura ideológica torna-se alienante e induz o trabalhador a desempenhar tarefas laborais sem reflexões sobre as condições degradantes de trabalho e sobre sua exploração em prol da reprodução do capital. Esse processo alienante advém da força do conjunto dos princípios da flexibilidade que impõem condições flexíveis ao trabalhador, presentes tanto dentro da fábrica e quanto em sua vida sociocultural.

A flexibilidade captura a capacidade de reflexão do trabalhador sobre as condições de trabalho e sobre as tarefas executadas no chão de fábrica. leva-o a desenvolver habilidades diversas mediante a multifuncionalidade exigida pela produção flexível, torna-o desprovido da especialização e o conduz a agir de acordo com as regras do mercado de trabalho, perfazendo um processo de precarização contínua do trabalho.

As adaptações impostas ao trabalhador objetivam cumprir as prioridades do JIT e do Kanban, cuja base é a flexibilidade. Com isto, as linhas de produção são balanceadas para que a produção esteja ajustada às variações da demanda, possibilitando uma subserviência dos funcionários à máquina ou à tecnologia e apresentando poucas ocorrências que levem a desperdícios ou a atrasos no processo produtivo, ou seja, há o aproveitamento total do tempo pela produção capitalista. Nesse sentido, Alves (1999, p. 87) afirma que: "A flexibilidade torna-se, no sentido geral, um atributo da própria organização social da produção".

Nota-se que dentro do espaço da fábrica da MMCB, há a presença de trabalhadores terceirizados, o que marca outra etapa na flexibilização das condições sociais do trabalho e da produção. As condições de trabalho são diferenciadas, pois alguns setores funcionam com trabalhadores próprios da montadora e outros com terceirizados, que, por sua vez, recebem salários inferiores aos dos trabalhadores da montadora. Essa diferenciação salarial entre funcionários que 
desempenham tarefas semelhantes leva ainda mais a um processo de fragmentação social no chão de fábrica e cria relações de poder antagônicas entre trabalhadores de forma a enfraquecer o processo de organização sindical e social da categoria.

Outras formas de flexibilização estão contidas na remuneração dos trabalhadores, entre as quais está a disponibilização de cartões de créditos (alimentação e farmácia) pela empresa, que disponibiliza mensalmente uma quantia em dinheiro para compra de bens de consumo por parte dos trabalhadores nos estabelecimentos comerciais credenciados, em vez de embutir esse crédito mensalmente no salário do trabalhador, contribuindo dessa forma para aumentar sua contribuição previdenciária. Em uma análise empírica, observa-se que são negados ao trabalhador um salário maior e uma receita maior advinda de tributos trabalhistas pagos ao Estado. Outro ponto é que os trabalhadores terceirizados possuem um cartão com crédito menor do que os trabalhadores da montadora.

Contudo, nota-se que as técnicas do JIT e os sistemas de gestão da produção do Kanban adotados nesta montadora contribuem para realçar ainda mais o processo de exclusão social e de subserviência do ser humano às condições do capital. Destaca-se ainda que a flexibilização não é imposta ao trabalhador apenas no processo produtivo que ocorre no chão de fábrica, mas também em sua vida social, seja no lar, no lazer, enfim, no seu cotidiano.

\section{CONSIDERAC̣ÕES FINAIS}

Com base nas reflexões teóricas e empíricas realizadas sobre o Toyotismo por meio do JIT e do Kanban, enfatiza-se a gerência e a organização do fluxo da produção. Para que os produtos fluam de forma contínua nas diversas fases do processo produtivo, tem-se a adoção de técnicas de reposição de peças no chão de fábrica. Para tais reflexões, abordou-se como esse processo se realiza na linha de montagem da indústria automotiva Mitsubishi, identificando que a empresa usa os supermercados, andon, kaisen e sequenciado para realizar a produção de veículos.

Observou-se também que o uso constante desses procedimentos de abastecimento leva a uma intensificação do ritmo do trabalho, determinado externamente pela demanda que provém do mercado de consumo, e impacta severamente as condições de trabalho dentro da fábrica, por meio da adoção de técnicas de gestão flexíveis do trabalho, tais como: multifuncionalidade, trabalho em equipe, terceirização.

A flexibilidade do trabalho cria um processo de subjunção do trabalhador aos ditos do capital, mas o captura em sua condição sócio-histórica, tornando esse trabalhador subordinado a uma ideologia imposta pela indústria toyotizada, que ultrapassa os limites do processo produtivo dentro da fábrica e alcança vida em sociedade, o convívio familiar, social e cultural do trabalhador. 
Por fim, constata-se que o Toyotismo, assim como o Fordismo, não consegue eliminar a precarização do trabalho no espaço fabril, ao contrário, acirra-a e superlativiza a separação entre trabalhadores e meios de produção. A esteira na fábrica moderna intensifica o ritmo da produção e consequentemente o ritmo do trabalho, unida ao uso de inovações tecnológicas, impõe-se dessa forma um ambiente estressante, tenso e propício a impactos emocionais e psicológicos sobre os trabalhadores que possuem metas diárias de produção a serem cumpridas.

\section{REFERÊNCIAS}

ABRAMIDES, M. B. C.; CABRAL, M. do S. R. Regime de acumulação flexível e saúde do trabalhador. Perspectiva, v. 17, n. 1 São Paulo, jan./mar. 2003. Disponível em: $<$ http://www.scielo.br/pdf/spp/v17n1/v17n1a01.pdf>. Acesso em: 5 maio 2015. ALVES, G. Dimensões da Reestruturação Produtiva: ensaios de sociologia do trabalho. 2. ed. Londrina: Praxis; Bauru: Canal 6, 2007.

. Trabalho e mundialização do capital: a nova degradação do trabalho na era da globalização. 2. ed. Londrina: Praxis, 1999. 185 p.

ANFAVEA. Estatísticas. Disponível em: <http://www.anfavea.com.br/tabelas.html>. Acesso em: 22 set. 2015.

ANTUNES, R. Os sentidos do trabalho: ensaio sobre a afirmação e a negação do trabalho. 2. ed. São Paulo: Boitempo, 2009. 287 p.

CHESNAIS, F. A mundialização do capital. Tradução de Luis Leiria Silva Foá. São Paulo: Xamã, 1996.

DAL FORNO, A. J.; TUBINO, D. F.; VALLE, A. C. R. do. Implementação de Kanban de fornecedor, transporte e produção: estudo de caso em empresa de cabines de máquinas agrícolas. ENCONTRO NACIONAL DE ENGENHARIA DA PRODUÇÃO, 27. Foz do Iguaçu-PR. Anais... Foz do Iguaçu-PR: Associação Brasileira de Engenharia de Produção, 2007. Disponível em: <http://www.abepro.org.br/biblioteca/ ENEGEP2007_TR570426_9676.pdf>. Acesso em: 5 maio 2015.

FRANCA, G. C. O trabalho no espaço da fábrica: um estudo da General Motors em São José dos Campos (SP). São Paulo: Expressão Popular, 2007. 176 p.

HECKERT, C. R.; FRANCISCHINI, P. G. Variações do Just-in-Time na indústria automobilística brasileira. Disponível em: <http://www.abepro.org.br/biblioteca/ enegep1998_art169.pdf>. Acesso em: 5 maio 2015.

KIYOHARA, D; ALMEIDA, D. A. Gerenciando o abastecimento de itens menores, via sistema Kanban, em uma linha de montagem da indústria automobilística - estudo de caso e recomendações de melhorias. Revista Pesquisa e Desenvolvimento Engenharia de Produção, Itajubá, n. 3, p. 1-14, out. 2004. Disponível em: <http://www.revista-ped. unifei.edu.br/documentos/V02N02/n3_art01.pdf>. Acesso em: 07 maio 2015.

MALAGUTI, M. L. A ideologia do modelo japonês de gestão. Ensaios FEE, Porto Alegre, v. 1, n. 17, p. 43-73, 1996. Disponível em: <http://revistas.fee.tche.br/index.php/ ensaios/article/viewArticle/1836>. Acesso em: 07 maio 2015. 
MMCB. O Projeto Anhanguera. Disponível em: <http://www.mitsubishimotors.com.br/ main.cfm/site/3/content/2>. Acesso em: 5 out. 2015.

NASSER, R.; SCAVONI, M. 20 anos de Mitsubishi Motors no Brasil. Encarte Publicitário, Mitsubishi Motors, 2010.

PAIVA, F. Plano Piloto. MIT Revista, n. 31. Disponível em: <http://www. mitsubishimotors.com.br/mitrevista/index31.cfm>. Acesso em: 26 fev. 2009.

PORTAL CATALÃO. Mitsubishi manteve as demissões em Catalão. Disponível em: $<$ http://www.portalcatalao.com.br/portal/noticias/seguranca/mitsubishi-manteve-asdemissoes-em-catalao,MTczMDc.html>. Acesso em: 22 set. 2015b.

. Mitsubishi faz demissões em massa de funcionários em Catalão. Disponível em: $<$ http://www.portalcatalao.com.br/portal/noticias/economia/mitsubishi-faz-demissoesem-massa-de-funcionarios-em-catalao,MTcyOTQ.html>. Acesso em: 4 out. $2015 \mathrm{a}$. PREFEITURA MUNICIPAL DE CATALÃO/ESTADO DE GOIÁS/MITSUBISHI. Protocolo de implantação de indústria montadora de veículos Mitsubishi. Goiânia, 1997.

SANTOS, M. A natureza do espaço. São Paulo: Edusp, 2002.

SILVA, M. V. da. A indústria automobilística em Catalão/Goiás: da rede ao circuito espacial da produção da MMC Automotores do Brasil S. A. 2011. 431 f. Tese (Doutorado em Geografia) - Instituto de Geografia, Universidade Federal de Uberlândia, Uberlândia, 2011.

SILVA, R. da. A implantação de Mitsubishi em Catalão: estratégias políticas e territoriais da indústria automobilística nos anos de 1990. 2002. 144 f. Dissertação (Mestrado em Geografia) - Instituto de Estudos Socioambientais, UFG/Goiânia, 2002. 
